\title{
Italian intersociety consensus statement on antithrombotic prophylaxis in hip and knee replacement and in femoral neck fracture surgery
}

\author{
F. Randelli $\cdot$ F. Biggi $\cdot$ G. Della Rocca • \\ P. Grossi • D. Imberti - R. Landolfi • \\ G. Palareti $\cdot$ D. Prisco
}

Published online: 19 January 2011

(C) The Author(s) 2011. This article is published with open access at Springerlink.com

\begin{abstract}
Anticoagulant prophylaxis for preventing venous thromboembolism (VTE) is a worldwide established procedure in hip and knee replacement surgery, as well as in the treatment of femoral neck fractures (FNF). Different guidelines are available in the literature, with quite different recommendations. None of them is a multidisciplinary effort as the one presented. The Italian Society for Studies on Haemostasis and Thrombosis (SISET), the Italian Society of Orthopaedics and Traumatology (SIOT), the association of Orthopaedists and Traumatologists of Italian Hospitals
\end{abstract}

F. Randelli-on behalf of Società Italiana di Ortopedia e

Traumatologia (SIOT).

F. Biggi—on behalf of Ortopedici Traumatologi Ospedalieri di Italia (OTODI).

G. Della Rocca, P. Grossi-on behalf of Società Italiana di Anestesia, Analgesia, Rianimazione e Terapia Intensiva (SIAARTI).

D. Imberti, R. Landolfi, G. Palareti, D. Prisco-on behalf of Società Italiana per lo Studio dell'Emostasi e della Trombosi (SISET).

\section{F. Randelli ( $\square)$}

Hip Department, Orthopedics and Trauma II, IRCCS Policlinico

San Donato, S. Donato Milanese, Milan, Italy

e-mail: filippo.randelli@fastwebnet.it

\section{F. Biggi}

Orthopaedic and Trauma Department, Belluno Hospital,

Belluno, Italy

G. Della Rocca

Anesthesia and Intensive Care Medicine,

University of Udine, Udine, Italy

P. Grossi

Regional Anesthesia and Pain Therapy Department, IRCCS

Policlinico San Donato, S. Donato Milanese, Milan, Italy

D. Imberti

Internal Medicine Department,

University Hospital of Ferrara, Ferrara, Italy
(OTODI), together with the Italian Society of Anesthesia, Analgesia, Resuscitation, and Intensive Care (SIAARTI) have set down easy and quick suggestions for VTE prophylaxis in hip and knee surgery as well as in FNF treatment. This inter-society consensus statement aims at simplifying the grading system reported in the literature, and its goal is to benefit its clinical application. Special focus is given to fragile patients, those with high bleeding risk, and those receiving chronic antiplatelet (APT) and vitamin $\mathrm{K}$ antagonists treatment. A special chapter is dedicated to regional anaesthesia and VTE prophylaxis.

Keywords Prevention of venous thromboembolism . Total knee replacement - Total hip replacement . Anticoagulant prophylaxis - Rivaroxaban · Dabigatran . Enoxaparin - Femoral neck fractures

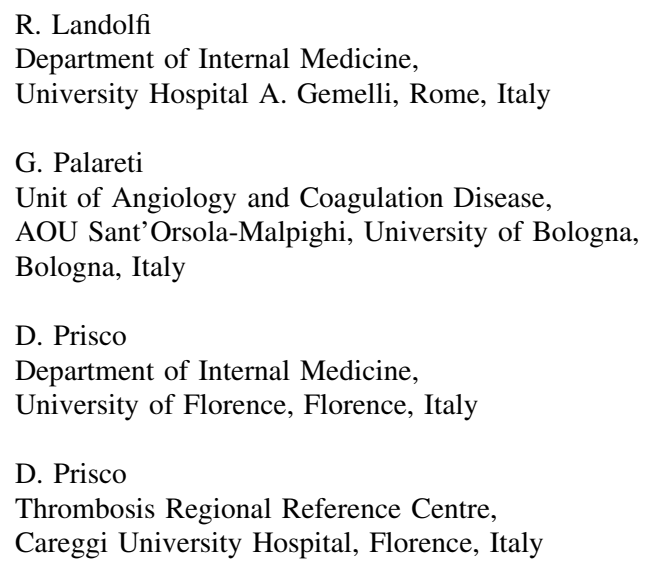




\section{Introduction}

Venous thromboembolism (VTE) represents a problem of relevant clinical and social impact. Recent data indicate an incidence of VTE of approximately 900,000 cases per year in the USA and of approximately 770,000 in Europe; in addition, pulmonary embolism (PE) is the direct cause of almost $10 \%$ of in-hospital deaths [1].

Anticoagulant prophylaxis for preventing VTE is a wellestablished procedure in hip (HR) and knee (KR) replacement surgery and in treating femoral neck fractures (FNF). Several meta-analyses indicate that in patients undergoing this kind of prophylactic treatment, an important reduction in symptomatic VTE is seen, with no relevant increase in major bleeding events [1-5]. These observations led the American College of Chest Physicians to generate universally recognized grade Ia recommendations on the need to initiate prophylaxis before all HR surgical interventions and to prolong treatment during the following 5 weeks. At present, pharmacological and/or mechanical prophylaxis is started in all cases of major orthopedic surgery (MOS), including elective HR and KR, and FNF surgery, as well as in several other cases of fracture (high-impact trauma, multiple fractures, multiple trauma) [1].

The Italian Society for Studies on Haemostasis and Thrombosis (SISET) has been focussing its research efforts on this topic for many years $[2,3]$. When the need to formulate practical recommendations arose in the world of orthopedics and traumatology, the Italian Society of Orthopaedics and Traumatology (SIOT) and the association of Orthopaedists and Traumatologists of Italian Hospitals (OTODI) identified SISET and the Italian Society of Anesthesia, Analgesia, Resuscitation and Intensive Care (SIAARTI) as their natural counterparts. This intersociety consensus statement aims at simplifying the grading system reported in the literature, and its goal is to improve its clinical application. For this reason, we believed that there was no need to define the strength of recommendations provided, as national and international dedicated guidelines already exist [1-5]. This statement is therefore addressed to the Italian scientific community and institutions with the aim of attaining good clinical practice in the profession.

The present statement will be published in the Journals of the different Societies participating in this consensus.

\section{Purpose}

Four purposes have been identified:

1. Keeping patients as safe as possible concerning the possibility of a thromboembolic event as a potential sequela in case of HR, KR, or FNF surgery in adults.

2. Reducing the possible complications linked to antithrombotic prophylaxis following HR, KR, or FNF surgery as much as possible.

3. Providing all specialists involved with unequivocal indications on the types of antithrombotic prophylaxis to be followed, in keeping with data reported in the national and international literature and with the laws in force in Italy.

4. Supplying useful suggestions on daily clinical practice in all situations in which no clear evidence is provided.

\section{Patients}

Patients were subdivided into three groups:

- Patients at high risk of VTE;

- Patients at high risk of bleeding;

- Particular or "fragile" patients requiring individualized treatment.

\section{Patients at high risk of VTE}

All patients undergoing HR, KR, or FNF surgery are at high risk of VTE and must follow an antithrombotic prophylaxis protocol. In-depth hematological and instrumental screening in quest of additional risk factors for thromboembolism is not believed to be essential, as knowledge of these factors would not alter the

Table 1 Patients at high risk of bleeding and patients who need careful evaluation for possible risk of bleeding

\begin{tabular}{ll}
\hline Patients at high risk of bleeding & Patients to be carefully evaluated for possible risk of bleeding \\
\hline Prolonged PT (INR $>1.5$ ) & Prolonged APTT (except antiphospholipid antibody syndrome) \\
Thrombocytopenia $<50,000 / \mu 1$ & \\
Known bleeding diathesis & Severe CRF (creatinine clearance $<30 \mathrm{ml} / \mathrm{min})$ \\
Chronic liver disease with prior bleeding episodes & Family or personal history of major bleeding \\
Multiple trauma (ISS $\geq 15)$ & $\begin{array}{c}\text { Concomitant use of drugs affecting hemostasis } \\
\text { (e.g., antiplatelet drugs, anti-inflammatory drugs) }\end{array}$ \\
\hline
\end{tabular}

$P T$ prothrombin time, INR International normalized ratio, ISS injury severity score, APTT antiplatelet treatment, $C R F$ chronic renal failure 
prophylactic strategies. An exception is made for patients with past episodes of deep vein thrombosis (DVT) and/or pulmonary embolism, who require an individualized preventive/curative approach.

Patients at high risk of bleeding

Patients at high risk of bleeding are described in Table 1.

Fragile patients

Fragile patients requiring individualized treatment are those who present with:

- Body weight $<50 \mathrm{~kg}$

- Age $>75$ years

- Moderate chronic renal failure (CRF) (creatinine clearance $30-50 \mathrm{ml} / \mathrm{min}$ )

The creation of a personalized, shared folder for thrombotic and hemorrhagic risk assessment and initiation of adequate thromboprophylaxis is suggested in all hospital settings. Furthermore, we recommend that the creation of this document be suggested by all administrations involved (hospital directorate, local health authority, regional administration, etc.).

\section{Type of prophylaxis}

\begin{tabular}{ll}
\hline Pharmacological & LMWH, FON, NOA, VKA, UH \\
Mechanical & Active (IPC, VFP) \\
& Passive (GCS) \\
Combined & Pharmacological + mechanical
\end{tabular}

LMWH low-molecular-weight heparin, FON fondaparinux, NOA new oral anticoagulants, $U H$ unfractionated heparin, $V K A$ vitamin $\mathrm{K}$ antagonists, VFP venous foot pump, IPC intermittent pneumatic compression, GCS graduated compression stockings
Pharmacological prophylaxis

- Pharmacological prophylaxis is based on low-molecular-weight heparin (LMWH), fondaparinux (FON), and new oral anticoagulants (NOA).

- Aspirin must not be used for VTE prophylaxis, as indicated by its label and by current guidelines.

- Unfractionated heparin (UH) must not be used considering that its efficacy is lower than that of LMWH, it has a short half-life, and it more frequently induces thrombocytopenia.

- Vitamin K antagonists (VKA) should not be administered because they are difficult to manage and maintain within a range of therapeutic anticoagulation [International normalized ratio (INR) ranging between 2 and 3].

Exceptions are possible but must be evaluated on an individualized basis with the consultant cardiologist or an expert in hemostasis and thrombosis.

\section{Low-molecular-weight heparin (LMWH)}

Concerning HR and KR, no differences in efficacy and safety have been reported between LMWH preoperative and postoperative first administration (Table 2) [6, 7]. LMWH labels in Italy, however, require a preoperative first administration except for bemiparin and dalteparin (for the latter only in hip surgery).

\section{Fondaparinux (FON)}

Fondaparinux has proved to be effective and safe in VTE prevention in HR, KR, and FNF (Table 3) [8]. In particular, FON has been reported to be more effective than LMWH (only demonstrated by decrease in phlebography-proven asymptomatic DVT) with modest, although statistically

Table 2 Dosage and time of administration of low-molecular-weight heparin (LMHW) available in Italy

\begin{tabular}{|c|c|c|}
\hline $\begin{array}{l}\text { Active } \\
\text { principle }\end{array}$ & Brand name & Dosage and time of administration \\
\hline Enoxaparin & Clexane $^{\circledR}$ & $4,000 \mathrm{IU} 12 \mathrm{~h}$ before surgery, then 4,000 IU/day \\
\hline Nadroparin & $\begin{array}{r}\text { Fraxiparine }{ }^{\circledR} \\
\text { Seleparin }\end{array}$ & $\begin{array}{l}38 \mathrm{IU} / \mathrm{kg} 12 \mathrm{~h} \text { before surgery and } 12 \mathrm{~h} \text { after, } 38 \mathrm{IU} / \mathrm{kg} \text { every } 24 \mathrm{~h} \text { during the } 3 \text { days following surgery, } \\
\text { thereafter increasing the dose to } 57 \mathrm{IU} / \mathrm{kg} / \text { day }\end{array}$ \\
\hline Dalteparin & Fragmin $^{\circledR}$ & $\begin{array}{l}5,000 \mathrm{IU} 8-12 \mathrm{~h} \text { before surgery, then } 5,000 \mathrm{IU} / \text { day. Alternatively } 2 \mathrm{~h}, 500 \mathrm{IU} 1-2 \text { before surgery }{ }^{\mathrm{a}} \text { and } \\
2,500 \mathrm{IU} 8-12 \mathrm{~h} \text { after, thereafter either } 5,000 \mathrm{IU} / \text { day or (only in hip surgery) } 2,500 \mathrm{IU} 4-8 \mathrm{~h} \text { after surgery } \\
\text { then } 5,000 \mathrm{IU} / \text { day }\end{array}$ \\
\hline Bemiparin & Ivor $^{\circledR}$ & $3,500 \mathrm{IU} 6 \mathrm{~h}$ after surgery, then 3,500 IU/day. Alternatively $3,500 \mathrm{IU} 2 \mathrm{~h}$ before surgery ${ }^{\mathrm{a}}$, then $3,500 \mathrm{IU} / \mathrm{day}$ \\
\hline Parnaparin & Fluxum $^{\circledR}$ & $0.4 \mathrm{ml}(4,250$ anti-Xa IU) $12 \mathrm{~h}$ before surgery, then $0.4 \mathrm{ml}(4,250$ anti-Xa IU)/day \\
\hline Reviparin & Clivarin $^{\circledR}$ & $0.4 \mathrm{ml}(4,200$ anti-Xa IU) $12 \mathrm{~h}$ before surgery, then $0.4 \mathrm{ml}(4,200$ anti-Xa IU)/day \\
\hline
\end{tabular}

${ }^{a}$ Although reported by the product label, this type of prophylaxis is not recommended 
Table 3 Dosage and time of administration of Fondaparinux

\begin{tabular}{|c|c|c|}
\hline Active principle & Brand name & Dosage and time of administration \\
\hline Fondaparinux & ARIXTRA $^{\circledR}$ & $\begin{array}{l}2.5 \mathrm{mg} \text { at least } 6 \mathrm{~h} \text { after surgery, then } 2.5 \mathrm{mg} / \mathrm{day}^{\mathrm{a}} \\
\text { If creatinine clearance } 20-50 \mathrm{ml} / \mathrm{min} 1.5 \mathrm{mg}^{\mathrm{b}}\end{array}$ \\
\hline
\end{tabular}

${ }^{a}$ In agreement with the latest edition of the American College of Chest Physicians (ACCP) guidelines [1], initiation may be postponed up to $24 \mathrm{~h}$ after the end of the intervention [9], although this has not been included in the label as yet

b According to the recent guidelines of the European Society of Anaesthesiology [10], FON is contraindicated if creatinine clearance $<30 \mathrm{ml} /$ $\min$

Table 4 Dosage and time of administration of available new oral anticoagulants (NOA)

\begin{tabular}{|c|c|c|}
\hline Active principle & Brand name & Dosage and time of administration \\
\hline Dabigatran $^{a}$ & $\operatorname{Pradaxa}^{\circledR}$ & $110 \mathrm{mg} 1-4 \mathrm{~h}$ after surgery, then $220 \mathrm{mg} /$ day \\
\hline (antifactor IIa) & & $\begin{array}{l}\text { If age }>75 \text { years or creatinine clearance } 30-50 \mathrm{ml} / \mathrm{min} \\
\text { or amiodarone intake, } 75 \mathrm{mg} 1-4 \mathrm{~h} \text { after surgery, then } 150 \mathrm{mg} / \text { day }\end{array}$ \\
\hline $\begin{array}{l}\text { Rivaroxaban }^{\mathrm{b}} \\
\text { (antifactor Xa) }\end{array}$ & Xarelto $^{\circledR}$ & $10 \mathrm{mg} 6-10 \mathrm{~h}$ after surgery, then $10 \mathrm{mg} /$ day \\
\hline
\end{tabular}

$\bar{a}$ Dabigatran has proved not to be inferior to low-molecular-weight heparin (LMWH) both in terms of efficacy and safety. As concerns dabigatran, in the literature, there is no information available on patients undergoing regional anaesthesia [11, 12]

b Rivaroxaban has shown to have greater efficacy than LMWH, with overlapping safety [13-16]. An analysis performed after publication of rivaroxaban registration study confirmed its safety in patients undergoing neuraxial anesthesia

significant, increase in bleeding and need for transfusions (with no related increase in fatal hemorrhage, in critical organs, or need for reintervention).

\section{New oral anticoagulants (NOA)}

New oral anticoagulants (dabigatran and rivaroxaban) have proved to be effective and safe in VTE prevention in HR and KR (Table 4) [11-16]. On the other hand, no direct comparison has ever been made between the two drugs, allowing for a definite confirmation of any different efficacy and safety. There is no evidence in the literature concerning the use of NOA in patients undergoing FNF surgery and concerning prolonged prophylaxis after KR; furthermore, experience in fragile patients is limited. Although these drugs do not require laboratory monitoring, they have been shown to prolong PT and APTT.

\section{Mechanical prophylaxis}

Mechanical prophylaxis is based on the use of graduated compression stockings (GCS) and on intermittent pneumatic compression (IPC) devices [17]. GCS (thigh-to-foot or knee-to-foot) increase the effectiveness of pharmacological prophylaxis, must be used until recovery of good mobility with autonomous de-ambulation (best if used on both legs), must be correctly positioned avoiding the "tourniquet effect," and must not be used in the presence of peripheral arterial disease or diabetic neuropathy. IPC devices (either sural or plantar) have a high efficacy and enhance the action of anticoagulant drugs, but there is a low compliance by nurses and patients as concerns their management.

\section{When should prophylaxis be started?}

Patients with femoral neck fracture (FNF)

Selection and initiation of the prophylactic treatment to be followed strongly depend on the adopted schedule:

- If surgery is performed on an emergency basis (within $24 \mathrm{~h}$ ), LMWH may be used (starting $12 \mathrm{~h}$ before or $12 \mathrm{~h}$ after) or, alternatively, FON (starting at least $6 \mathrm{~h}$ after the end of the intervention and, in any case, within $24 \mathrm{~h}$ ).

- If surgery is postponed, LMWH must be administered early. In this case, there is no information available on the possibility of initiating FON 6-8 $\mathrm{h}$ after the end of the intervention, thus producing a shift between the two anticoagulant drugs. At present, no recommendation can be made on this subject.

- NOA must not be used, as no study pertaining to FNF has been published. 
Patients candidate for hip (HR) and knee (KR) replacement

In the literature, no significant difference in efficacy and safety has been reported between preoperative and postoperative initiation of LMWH in HR and KR [1, 6, 7]. Consequently, the choice must be based on evidence reported in published studies as well as on what is indicated on LMWH labels, which in Italy require initiation of prophylaxis $12 \mathrm{~h}$ before surgery, except for dalteparin and bemiparin (Table 2). Both FON and NOA must always be started postoperatively (Tables 3,4 ).

\section{How long should pharmacological prophylaxis last?}

Concerning the duration of pharmacological prophylactic treatment, if LMWH is used, therapy should last a minimum of 10 days in all patients, with a strong recommendation to protract prophylaxis for 35 days after HR and FNF surgery and the suggestion - with a lower level of evidence - to protract treatment similarly in patients undergoing KR surgery $[1,18]$. Regardless, in Italy, it is standard procedure to protract prophylaxis for 35 days even after KR surgery. This approach is also suggested for FON therapy. As far as NOA are concerned, indications on duration of treatment derive from registration studies and are reported on the labels of dabigatran and rivaroxaban:

- With dabigatran, duration is $4-5$ weeks in HR and 10 days in KR surgery;

- With rivaroxaban, duration is 5 weeks in HR and 2 weeks in KR surgery.

The safety of 5-week treatment with NOA has been proven in HR studies, which suggest the reliability and feasibility of this prophylaxis duration after KR as well. Lastly, it must be remembered that further protraction of prophylaxis (longer than suggested duration) has to be addressed in patients who, for different reasons (prolonged recumbence, additional risk factors), are at risk of developing VTE complications for a longer period than usual.

\section{Anesthesia techniques and initiation of pharmacological prophylaxis}

No particular problem is identified in relation to general anesthesia (GA). On the other hand, regarding regional anesthesia (RA), timing must be carefully respected with epidural or intrathecal anesthesia, whereas there are no contraindications in perineural block $[19,20]$. It is widely accepted that RA reduces the risk of VTE and that the correct timing (prophylaxis/RA administration and, if present, catheter removal) is crucial to prevent complications. Actually, all anticoagulants used in VTE prevention in HR, $\mathrm{KR}$, and FNF are closely related to the risk of developing epidural hematoma. In particular, upon removal of the epidural catheter, drug effectiveness, half-life $\left(\mathrm{T}_{1 / 2}\right)$, and time to maximum concentration $\left(T_{\max }\right)$ must be assessed: as a general rule, the recommendation is made to wait at least 2 halflives before removal, resuming pharmacological prophylaxis after $8 \mathrm{~h}$ (period required for clot formation) minus $\mathrm{T}_{\max }$.

To simplify:

LMWH and RA [19, 20]

$\mathrm{T}_{1 / 2}: 4 \mathrm{~h}$

$\mathrm{T}_{\max }: 4 \mathrm{~h}$

Last administration before catheter removal: at least $12 \mathrm{~h}$.

First administration after catheter removal: at least after 6-8 h.

If LMWH is administered twice daily, either at the prophylactic or therapeutic dosage, $24 \mathrm{~h}$ must pass after catheter removal before proceeding with the following dose.

If traumatic puncture, consider the possibility of initiating prophylaxis after $24 \mathrm{~h}$.

FON and RA [21]
$\mathrm{T}_{1 / 2}: 17 \mathrm{~h}$
$\mathrm{~T}_{\text {max }}: 1 \mathrm{~h}$

If FON is administered at the therapeutic dosage, no central block must be performed.

Last administration before catheter removal: at least $36 \mathrm{~h}$.

First administration after catheter removal: at least after $12 \mathrm{~h}$.

If traumatic puncture, consider the possibility of initiating prophylaxis after $24 \mathrm{~h}$.

\section{$N O A$ and $R A$ [10]}

As concerns the relationship between NOA and RA, there is no information available (randomized clinical studies) concerning timing and method of use; therefore, refer to what is reported on the product label:

- Dabigatran - not recommended in patients who must undergo anesthesia requiring the use of postoperative permanent epidural catheters, as no information is reported in the literature.

- Rivaroxaban-last administration $18 \mathrm{~h}$ before removal, resume administration $6 \mathrm{~h}$ after removal; recent guidelines of the European Society of Anaesthesiology suggest a longer period between last rivaroxaban dose and epidural catheter removal (22-26 h) [10]. 
Table 5 Correlation between anesthesia and antiplatelet treatment (APT)

\begin{tabular}{lll}
\hline Regional anesthesia $^{\mathrm{a}}$ & & General anesthesia \\
\hline Patients on APT with & & Patients on APT \\
\hline $\begin{array}{l}\text { Acetylsalicylic acid (ASA): do not interrupt } \\
\text { in case of secondary prevention (75-100 mg/day) }\end{array}$ & Ticlopidine-interrupt 10 days pre-op & GA always feasible \\
$\begin{array}{l}\text { IIb/IIIa inhibitors } \\
\text { Abciximab-RA contraindicated }\end{array}$ & Clopidogrel—interrupt 7 days pre-op & $\begin{array}{c}\text { Risk of surgical bleeding must always } \\
\text { be considered before surgery }\end{array}$ \\
$\begin{array}{l}\text { Eptifibatide-interrupt } 8 \text { h pre-op } \\
\text { Tirofiban-interrupt } 4 \mathrm{~h} \text { pre-op }\end{array}$ & \\
\hline
\end{tabular}

a APT, if no bleeding occurs, must be resumed the day following the intervention and, in the presence of epidural catheterization, after catheter removal

Anesthesia/patient correlation in antiplatelet treatment

See Table 5 .

\section{Management of vitamin $K$ antagonist (VKA) patients}

The main purpose is leading patients to surgical intervention with an adequate hemostasis and reducing the risk of thromboembolism as much as possible.

Femoral neck fracture (FNF) patients

Intervention should be delayed and INR measured: If INR > 2, administer vitamin K $10 \mathrm{mg}$ in $100 \mathrm{ml}$ of saline or glucose solution i.v. and measure INR every $6 / 8 \mathrm{~h}$ until INR $<2$ is attained. If INR $<2$, start LMWH administration at the prophylactic dose and timing (4,000-5,000 IU/day), plan surgical intervention as soon as possible, and request consultation by a cardiologist and/or by an expert in hemostasis and thrombosis to plan VKA resumption after surgery.

Patients candidate for elective hip (HR) and knee (KR) replacement

Each hospital should have a written and shared protocol concerning the management of VKA patients who have to undergo major lower-limb orthopedic surgery; consultation by a cardiologist and/or an expert in hemostasis and thrombosis should be requested to prepare a personalized schedule addressing VKA interruption and resumption; the timing of surgery must be respected, and the procedure should not be delayed.

\section{Management of antiplatelet treatment (APT) patients}

Aspirin administered as primary prevention must be interrupted 7 days before elective surgery, whereas it must be interrupted upon hospital admission in patients with FNF planned for surgery. Aspirin administration as secondary prevention (in patients with prior cardiovascular events) must be continued at the dose of 75-100 mg/day.

Femoral neck fracture (FNF) patients

For FNF, APT patients should undergo surgery as soon as possible. For patients on clopidogrel or ticlopidine (or dual anti-aggregation), request consultation by a cardiologist and/or an expert in hemostasis and thrombosis.

Patients candidate for hip (HR) and knee (KR) replacement

Administration of clopidogrel or ticlopidine must be interrupted 7 and 10 days before surgery, respectively, whereas in patients receiving dual anti-aggregation (aspirin and clopidogrel), surgery must be delayed if clopidogrel interruption is expected during the following months; if interruption is not expected, request consultation by a cardiologist and/or an expert in hemostasis and thrombosis. In all such patients, as a general rule, resume APT as soon as possible and regardless, once hemostasis is achieved.

\section{Patients at high risk of bleeding}

In patients at high risk of bleeding, the absolute contraindication to pharmacological prophylaxis is represented by ongoing major bleeding. In this case, mechanical prophylaxis is indicated. The relative contraindication is applied to all the other conditions for which patients are at high risk of bleeding reported in Table 1 . In these cases, pharmacological or transfusional correction of the hemostatic defect is recommended whenever indicated and feasible, considering mechanical and/or dedicated pharmacological prophylaxis (dose reduction, postoperative initiation). 


\section{Special cases or fragile patients}

Providing precise directives for managing such patients goes beyond the purpose of this consensus statement; the only indication is to pay extreme attention to them and to request consultation by an expert on hemostasis and thrombosis. Management of anticoagulant drugs in obese patients [body mass index $(\mathrm{BMI})>30$ ] is not considered to be different from what occurs with other patients. In patients with renal failure, labels of the single drugs administered must be referred to, and careful clinical monitoring must follow.

\section{General considerations}

- Postoperative mobilization must be started as soon as possible.

- Bed-rest patients should receive lower-limb mobilization exercises.

- General practitioners and patients should be informed how to recognize signs and symptoms of DVT and PE, how to correctly manage home prophylaxis, and about the risks of omitting it.

- Pharmaceutical companies and regulatory authorities (Italian Medicines Agency, etc.) should keep labels updated in agreement with scientific evidence reported in the literature.

\section{Conclusions}

This document represents a consensus statement of Italian experts, with information based on scientific knowledge and labels available during the summer of 2010, and it will be disseminated by the four societies via different modalities (society journals, society Web sites, symposia organized within national congresses, etc.). A periodical revision of this document is expected, which will be of particular importance for the use of new anticoagulant drugs currently undergoing clinical development, some of which (edoxaban, betrixaban, and others) are still undergoing a preliminary trial phase. For other drugs (apixaban), studies are already available $[22,23]$ that prove their efficacy and safety in VTE prevention in HR and KR surgery. It is therefore likely that the number of drugs available for this type of prophylaxis will increase in the near future.

Acknowledgments Claudio Cimminiello worked in cooperation with Filippo Randelli, Davide Imberti, and Paolo Grossi in drawing up the first SIOT document in 2009.
Open Access This article is distributed under the terms of the Creative Commons Attribution License which permits any use, distribution and reproduction in any medium, provided the original author(s) and source are credited.

\section{References}

1. Geerts WH, Bergqvist D, Pineo GF, Heit JA, Samama CM, Lassen MR, Colwell CW (2008) American College of Chest Physicians. Prevention of venous thromboembolism American College of Chest Physicians evidence-based clinical practice guidelines (8th edn). Chest 133(Suppl):381S-453S

2. Prisco D, Violi F (2002) Linee guida per la profilassi del tromboembolismo venoso in chirurgia ortopedica maggiore: cosa pensa la Società Italiana per lo Studio dell'Emostasi e della Trombosi. Haematologica 87 (Suppl 4):11-13

3. Prisco D, Gruppo di lavoro per le linee guida sul tromboembolismo venoso della Società Italiana per lo Studio dell'Emostasi e della Trombosi (coordinatore Prisco D) (2003) Linee guida per la diagnosi, la profilassi e la terapia del tromboembolismo venoso. Haematologica 88 (Suppl 18):1-61

4. Prevention and treatment of venous thromboembolism (2006) International consensus statement. Int Angiol 25:1001-1161

5. Hill J (2010) Treasure T; National Clinical Guideline Centre for acute and chronic conditions. Reducing the risk of venous thromboembolism in patients admitted to hospital: summary of NICE guidance. BMJ 340:c95

6. Strebel N, Prins M, Agnelli G, Büller HR (2002) Preoperative or postoperative start of prophylaxis for venous thromboembolism with low-molecularweight heparin in elective hip surgery? Arch Intern Med 162:1451-1456

7. Raskob GE, Hirsh J (2003) Controversies in timing of the first dose of anticoagulant prophylaxis against venous thromboembolism after major orthopedic surgery. Chest 124:379S-385S

8. Turpie AG, Bauer KA, Eriksson BI, Lassen MR (2002) Fondaparinux versus enoxaparin for the prevention of venous thromboembolism in major orthopedic surgery. Arch Intern Med 162:1833-1840

9. Colwell CW Jr, Kwong LM, Turpie AG, Davidson BL (2006) Flexibility in administration of fondaparinux for prevention of symptomatic venous thromboembolism in orthopaedic surgery. J Arthroplasty 21:36-45

10. Gogarten W, Vandermeulen E, Van Aken H, Kozek S, Llau JV, Samama CM (2010) Regional anaesthesia and antithrombotic agents: recommendations of the European society of Anaesthesiology. Eur J Anaesthesiol 27(12):999-1015

11. Eriksson BI, Dahl OE, Rosencher N, Kurth AA, van Dijk CN, Frostick SP, Prins MH, Hettiarachchi R, Hantel S, Schnee J, Büller HR; RE-NOVATE Study Group (2007) Dabigatran etexilate versus enoxaparin for prevention of venous thromboembolism after total hip replacement: randomized, double-blind, noninferiority trial. Lancet 370:949-956

12. Eriksson BI, Dahl OE, Rosencher N, Kurth AA, van Dijk CN, Frostick SP, Kälebo P, Christiansen AV, Hantel S, Hettiarachchi R, Schnee J, Büller HR; RE-MODEL Study Group (2007) Oral dabigatran etexilate versus subcutaneous enoxaparin for the prevention of venous thromboembolism after total knee replacement. The RE-MODEL randomized trial. J Thromb Haemost 5:2178-2185

13. Eriksson BI, Borris LC, Friedman RJ, Haas S, Huisman MV, Kakkar AK, Bandel TJ, Beckmann H, Muehlhofer E, Misselwitz F, Geerts W, RECORD1 Study Group (2008) Rivaroxaban versus 
enoxaparin for thromboprophylaxis after hip arthroplasty. N Engl J Med 358:2765-2775

14. Kakkar AK, Brenner B, Dahl OE, Eriksson BI, Mouret P, Muntz J, Soglian AG, Pap AF, Misselwitz F, Haas S, RECORD2 Investigators (2008) Extended duration rivaroxaban versus shortterm enoxaparin for the prevention of venous thromboembolism after total hip arthroplasty: a double-blind, randomised controlled trial. Lancet 372:31-39

15. Lassen MR, Ageno W, Borris LC, Lieberman JR, Rosencher N, Bandel TJ, Misselwitz F, Turpie AG, RECORD3 Investigators (2008) Rivaroxaban versus enoxaparin for thromboprophylaxis after total knee arthroplasty. N Engl J Med 358:2776-2786

16. Turpie AG, Lassen MR, Davidson BL, Bauer KA, Gent M, Kwong LM, Cushner FD, Lotke PA, Berkowitz SD, Bandel TJ, Benson A, Misselwitz F, Fisher WD, RECORD4 Investigators (2009) Rivaroxaban versus enoxaparin for thromboprophylaxis after total knee arthroplasty (RECORD4): a randomised trial. Lancet 373:1673-1680

17. Hooker LA, Lachiewicz PF, Kelley SS (1999) Efficacy of prophylaxis against thromboembolism with intermittent pneumatic compression after primary and revision total hip arthroplasty. J Bone Joint Surg Am 81:690-696

18. Eikelboom JW, Quinlan DJ, Douketis JD (2001) Extended duration prophylaxis against venous thromboembolism after total hip replacement: a metaanalysis of the randomised trials. Lancet 358:9-15

19. Horlocker TT (2001) Low molecular weight heparin and neuraxial anesthesia. Thromb Res 101:141-154

20. Horlocker TT, Wedel DJ, Rowlingson JC, Enneking FK, Kopp SL, Benzon HT, Brown DL, Heit JA, Mulroy MF, Rosenquist RW, Tryba M, Yuan CS (2010) Regional anesthesia in the patient receiving antithrombotic or thrombolytic therapy: American society of regional Anesthesia and pain medicine evidence-based guidelines (3rd edn). Reg Anesth Pain Med 35:64-101

21. Singelyn FJ, Verheyen CC, Piovella F, Van Aken HK, Rosencher N, EXPERT Study Investigators (2007) The safety and efficacy of extended prophylaxis with fondaparinux after major orthopaedic surgery of the lower limb with or without a neuraxial or deep peripheral nerve catheter: the EXPERT study. Anesth Analg 105:1540-1547

22. Lassen MR, Raskob GE, Gallus A, Pineo G, Chen D, Portman RJ (2009) Apixaban or enoxaparin for thromboprophylaxis after knee replacement. N Engl J Med 361:594-604

23. Lassen MR, Raskob GE, Gallus A, Pineo G, Chen D, Hornick P, ADVANCE-2 investigators (2010) Apixaban versus enoxaparin for thromboprophylaxis after knee replacement (ADVANCE-2): a randomised double-blind trial. Lancet 375:807-815

\section{Appendix: web sites of interest}

www.chestnet.org: American College of Chest Physicians www.nice.org.uk: National Institute for Health and Clinical Excellence

www.otodi.com: Ortopedici e Traumatologi Ospedalieri D'Italia www.siaarti.it: Società Italiana di Anestesia Analgesia, Rianimazione e Terapia Intensiva

www.sign.ac.uk: Scottish Intercollegiate Guidelines Network www.siot.it: Società Italiana di Ortopedia e Traumatologia www.siset.org: Società Italiana per lo Studio dell'Emostasi e della Trombosi 